\title{
An information and cooperation portal for large public events in urban areas
}

\author{
W. Engelbach \& S. Frings \\ Fraunhofer IAO, Germany
}

\begin{abstract}
In urban areas, large public events are quite common and lead to peak usage of the urban transport systems. Their increasing number and complexity require clear planning and communication processes that involve all relevant parties for traffic and security issues. Besides overall organisational issues, the adequate reaction in case of unexpected incidents has to be prepared for. An information and cooperation portal for these purposes was designed for the region of Cologne; this is being implemented and currently tested against clear user requirements.

Keywords: information techniques and communications, transport security and safety, public transport systems, inter-modal transport systems, traffic management, urban transport strategies, urban transport management, mobility behaviour, policy frameworks.
\end{abstract}

\section{Introduction}

This paper presents the background and elaborates requirements for an information and cooperation portal for large public events, with specific attention to public transport and security concerns. It also outlines a first demonstrator that is currently being evaluated with several partners in Cologne, Germany.

\subsection{Background}

The increased mobility of many people and the cities' efforts to increase their attractiveness for citizens and visitors have led to a growing number of mass events. In addition to the daily use of public transport for work, leisure, shopping, etc., mass events mean increased demands on public transport. 
However, due to numerous private players, fragmented responsibilities, competition in rail traffic and outsourced departments, concerted action by all decision-makers is often becoming increasingly difficult even during the planning stages of a mass event.

In urban areas, large public events such as sport championships, open-airconcerts or town festivals are quite common and lead to peak usage of the urban transport systems. Their increasing number and complexity require clear planning and communication processes that involve all relevant parties for traffic and security issues.

In addition to this, mass events arouse international interest and have worldwide public visibility through television broadcasts, in Cologne, Germany, e.g. during the Soccer World Cup or the World Youth Day with the visit of the Pope. This situation offers an incentive for terrorists to attack such big events. Therefore, besides overall organisational issues, the adequate reaction in case of unexpected incidents such as thunderstorms or bomb warnings has to be prepared for in all involved organisations.

Visitors frequently use public transport for the arrival to and departure from a mass event because often neither the streets nor parking spaces are available for private traffic. Furthermore, the public transport is often already included in the admission charge for the respective event (combination ticket). In the public transport as well as at the stops and during changeovers, the danger of unsecure situations is increasing because of the spatial limitedness, missing orientation of foreign visitors and necessary waiting.

The guarantee of safety and even more security in the public traffic during large events is aggravated by the fact that a variety of public and private enterprises and organisations are involved. In such a way organisers, operators of the event locations, the responsible municipality, different transport companies, police and fire brigade work together before, during and after the event, but each of them under their own rules. Thus, the responsibilities, standard action plans and contact details of relevant persons are not transparent for every involved partner today. The complexity of protagonists is even growing further, for example because of increasing involvement of private security forces and the opening of regional transport markets.

\subsection{The project VeRSiert at a glance}

The German funded research project VeRSiert (networking of local passenger transport companies, relief personnel, organisers and passengers for greater security in public transport at mass events, funded by the German Federal Ministry of Education and Research, www.bmbf.de, Forschungsprogramm für die zivile Sicherheit, FKZ 13N9709; www.versiert.info; Project coordinator: Nahverkehr Rheinland (NVR)) addresses exactly those important aspects. The project aims at improving the security of event participants, security personnel and skilled help, as well as personnel of transport organisation during mass events, e.g. by simulation, mobile IT-services and video analytics. A central integrating element is an information and cooperation portal to support optimal information sharing and improved networking of all participants. 
The project started in mid 2008 with a number of concurrent research activities to gather ideas, flaws, experiences, etc., all contributing to the collection of requirements for the portal. The activities relevant for this are as follows:

- Analysis of current and past mass events in Cologne, Germany,

- analysis of possible unplanned incidents during mass events,

- analysis and documentation of processes established within the participating organisations when planning for and executing mass events,

- questioning German transport organisations regarding security and safety issues when planning for and executing mass events,

- questioning German municipalities having over 50.000 residents regarding security and safety issues when planning for and executing mass events.

From all of these research activities, as well as from the expertise and experience of the involved project partners Kölner Verkehrsbetriebe (KVB), Nahverkehr Rheinland (NVR) and City of Cologne, the requirements for the information and cooperation portal were gathered and documented. At the end of 2009 , a first version of the portal demonstrator was completed and is being tested by partners starting early 2010; the next software versions are due for April and October 2010.

\section{Definitions and state of the art}

Since the authors of this article focus on the information and cooperation portal designed and prototypically implemented in the VeRSiert project, this section is restricted to definitions concerning portals and state of the art systems similar to the VeRSiert portal.

According to Kirchhof [1] there are three different categories of systems supplying business information for different kinds of users using the Internet technologies:

- Internet and company websites used for the public presentation of the company and its products or services,

- intranets allowing employees within a company to share documents, calendars, manage projects and communicate with distributed employees,

- extranets allowing businesses to share documents, calendars, manage projects and communicate with distributed employees, partners, and customers, etc.

According to Shilakes [2] portals are defined as follows: "Enterprise Information Portals are applications that enable companies to unlock internally and externally stored information, and provide users a single gateway to personalised information needed to make informed business decisions." They are: ". . . an amalgamation of software applications that consolidate, manage, analyse and distribute information across and outside of an enterprise...". Company portals (enterprise information portals) can also provide personalised content as well as processes (e.g. workflows) tailored to suit the users' needs. 
Based on these definitions, the desired solution for the VeRSiert portal would be an "Extranet Portal" which is a mechanism based on Internet and Web technology for communicating both privately and selectively with permitted actors belonging to different organisations and having different needs to accomplish their work.

Nowadays, when implementing web-based software, there are always at least three ways to go: Taking an existing or open source tool and modifying it accordingly, using a tool to create the software, and doing programming work mostly manually, but reusing components. During the set-up of the VeRSiert consortium, the project coordinator NVR decided to select a software developing company that has experience in web-applications and had implemented (among others) a software tool for a German logistics service provider, from which several components could be reused for the VeRSiert demonstrator.

Since there are no comparable projects designing and implementing a portal to meet the VeRSiert objectives, the following paragraphs list some initiatives having similar objectives. So called "Ordnungspartnerschaften" are partnerships to assure order in which organisations like police, city administration, schools, universities, and public passenger transport companies have the same aim in improving public security and thereby cooperating on a very intense level. These networks create security concepts according to their needs [13, 14].

Another important initiative is the central office for regional security management and prevention (ZeRP - Zentralstelle für regionales Sicherheitsmanagement und Prävention) [15]. They aim at improving subjective and objective security in public passenger transport by collecting data on all relevant incidents within one database. This database is the decision base for goaloriented assignment of service and security personnel, findings about hazards and threads, as well as for the development of regional prevention strategies. ZeRP now has almost 30 members.

There are also a few related German and European projects worth mentioning:

- Eventverkehr - Development and evaluation of concepts for attractive, environment friendliness, and socially acceptable traffic design for mass events (http://www.eventverkehr.de/)

- Dybel - Integrated overall concept for a dynamic visitor guidance system (http://www.verkehrstechnologien.at/dybel/_/prog20/project664)

- $\quad$ interEvent - Integrated model for traffic planning and traffic control during mass events (http://www.salzburgresearch.at/research/gfx/interevent agit07_paper_final_camera_ready.pdf)

- $\bar{M}$ Modsafe - $\bar{M}$ odel-Based Safety Evaluation of Automation Systems (http://www.modsafe.eu/)

- Railprotect - Innovative Technologies for Safer and more Secure Land Mass-Transport Infrastructure under Terrorist Attacks (http://elsa.jrc.ec.europa.eu/showproject.php?id=13)

- Counteract - Cluster of User Networks in Transport and Energy Relating to Anti-terrorist ACTivities (http://www.counteract.eu/) 


\section{Analysis of the current situation}

At the beginning of the project, several research activities and surveys were performed, all aiming at analysing the current situation regarding mass events (including processes), unplanned incidents, and security and safety issues within the local public passenger transport in Germany as a whole and in the city of Cologne specifically. From these surveys, necessary requirements for the VeRSiert information and cooperation portal were derived. In addition, guidelines and security concept were reviewed, which help to prevent and to be better prepared for such attacks (see BBK [3], BMI [4], BMI [5], BMI [6], BMI [7], and VDV [8]).

\subsection{Analysis of relevant mass events and unplanned incidents}

The project VeRSiert started with the analysis of current and past mass events in Cologne, Germany. The project team was able to establish a classification scheme - using known methods like published in Bailey [9] and Hevner [10] - to describe mass events having 17 different dimensions and several possible occurrences for each dimension (Rossnagel [11]). Using this classification scheme, three different scenarios for mass events in Cologne were defined, which are the basis for all objectives defined within the project.

Those scenarios are a) "Cologne lights up" (Koelner Lichter), b) German soccer league games and c) German protestant church congress. Those types of events were chosen because of the following characteristics: a) very large event, occurring in similar ways since more than 10 years, b) smaller but more security relevant event, occurring very regularly, and c) extremely large event, covering more than one day but being a non-repetitive event in Cologne.

A similar analysis was performed for possible unplanned incidents that may occur during a mass event. The classification scheme consists of 13 dimensions and again several occurrences for each dimension. To further detail the three scenarios mentioned above, different types of unplanned incidents most relevant for an event type were chosen: a) accidental bodily injury, attack, discovery of abandoned suitcase, storm, b) broken down subway car, rampage, and c) bomb threat, wrongfully blocking of a passageway due to misjudgement.

\subsection{Process analysis before and during events in Cologne}

The third analysis performed in the first months of the project dealt with documenting the processes established within the participation organisations when planning for and going through the three types of events mentioned above. Relevant personnel of the city of Cologne, of the two transport companies NVR and KVB, as well as of the organisers of the events, were interviewed and the results were documented in a structured way. The derived technical and none technical requirements for the VeRSiert portal were formulated, discussed, prioritised and documented (see section 4). 


\subsection{Analysis of the current security situation in Germany}

One survey performed by the project partner Universität Wuppertal SVPT questioned 158 out of 440 transport organisations in written form throughout Germany about security and safety issues having three main objectives in mind:

1. Getting an overview of the integration of transport organisations when planning and executing mass events,

2. gathering specific ideas, measures, and experience to improve the security and safety in public transport,

3. getting an overview of management strategies to optimise the security and safety in public transport (e.g. operational and organisational structure, risk analysis, crisis management).

The survey showed, among many other results, that necessary communication structures between transport organisations, the city, security and health organisations, and the event manager when planning and executing mass events are - most of the time - in place and working. Nevertheless, most transport organisations think that having a computer supported information and cooperation portal has potential of optimising the processes between the involved actors. Some needs expressed in specific answers could be dealt with within the portal in the following ways:

- Need for inspecting and establishing information paths between police and transport organisations: providing documentation of information paths within the portal.

- Need for establishing common committees and forums between police and transport organisations to prevent and detect attacks: providing a communication platform and documents within the portal for relevant actors.

- Need for defining and prioritising critical objects (e.g. train stations, vehicles, passageways) between police and transport organisations using common ratings: providing an information platform and documents within the portal for relevant actors.

- Need for coordination of means and content of passenger information (e.g. loudspeaker announcements, optical passenger information systems): providing content for passenger information within the portal for relevant actors.

- Need for inspecting and coordination of evacuation concepts: providing up to date and consolidated evaluation concepts within the portal for relevant locations.

- Need for appointing security officers within the transport organisations: providing contact information about the security officers within the portal for relevant actors.

Another survey also performed by the project partner Universität Wuppertal SVPT questioned 69 out of 188 municipalities in Germany having more than 50.000 residents about security and safety issues when planning and executing mass events expecting to get information regarding the following issues:

- $\quad$ Type and topic of mass events, type and substance of unplanned incidents,

- duration and frequency of mass events, number of participants, 
- $\quad$ available emergency and crisis plans in case of unplanned incidents,

- available traffic control centres, as well as event specific control centres, and their cooperation,

- communication between actors and used communication means during the event approval phase.

The most common events are city festivals and sports events. This shows that the VeRSiert mass event scenarios mentioned above are in line with the current situation. Regarding the topic of unplanned events, the survey shows that hardly any incident specific emergency or crisis plans exist (aside from the plans used by police and fire department) or are known of. Only 13 answers of the survey covered information about specific unplanned incidents, mostly caused by bad weather or technical breakdowns. This shows that the VeRSiert incident scenarios mentioned above are as well in line with the current situation.

The operation of integrated and cooperative control centres during a mass event is restricted to events in cities with more than 500.000 residents. Control centres operated by transport organisations are more common, very common in cities with more than 200.000 residents. However, mass event specific control centres are very rare. Telephone landlines, mobile phones, (digital) radio communication are the common means for communication in control centres between the involved parties. The focus lies on the coordination of traffic and traffic blockings. The direct personal contact between involved parties is very important for the German municipalities before and during mass events.

Common means for communication between parties of mass events are based mainly on personal contact and using email. Mentioned deficits are nontransparent decision paths, unreliability and unattainability of the event manager, frequently changing contact persons, as well as incomplete or out of date planning documents. Those current flaws call for an "event specific extranet" giving relevant actors access to information in form of up to date documents, calendars, lists of tasks, contact data, and events, etc. - the VeRSiert information and cooperation portal.

There is hardly any experience of using event specific "extranets" or other computer supported solutions. This shows, that the VeRSiert approach is highly innovative and on demand. The planned web-based solution does not contradict personal contacts but supports the communication, cooperation, and coordination between involved actors.

\section{The concept of the information and cooperation portal}

The VeRSiert prototypical implementation of the portal follows the design science approach (Vaishnavi [12]): knowing a problem, suggesting solutions through requirements, developing main features to solve the problem, as well as evaluating the implementation with relevant users. Having in mind that several organisations, and therefore many people in those organisations, need to cooperate when planning and executing a mass event, the portal needs to offer the following basic functions: 
For each mass event to be planned a database entry needs to be generated, allowing event attributes to be put into the system. Basic attributes are event name, location, date, time, etc. The next step would be to assign participating organisations and their personnel to the event, selecting those from the database.

According to the underlying role and access model, users have different views on the event information. The following user groups are intended: super administrator, administrator per organisation, event authorisation instance, active user, passive user, and event manager. A user can now - according to his rights upload documents, invite other users to meetings, put appointments into a calendar, assign necessary tasks to himself, give advice according to his experience with past events, review advice given by others, or view interfaces to relevant external systems.

When visiting the event information in the portal, the user, is able to receive automatically generated information due to underlying rules. For example: A specific rule says, that a soccer game between Cologne and Dortmund is very security sensitive, and therefore needs an additional train for the Dortmund fans, then this train needs to be ordered at least 6 weeks prior to the game. If this has not happened, the appointed user will receive this reminder information through the portal. Other users can view, if this task has been completed yet.

As a summary, the main functions of the portal are event and incident management (viewing, creating and updating event and incident data), assignment of participating roles, document, task and appointment management,

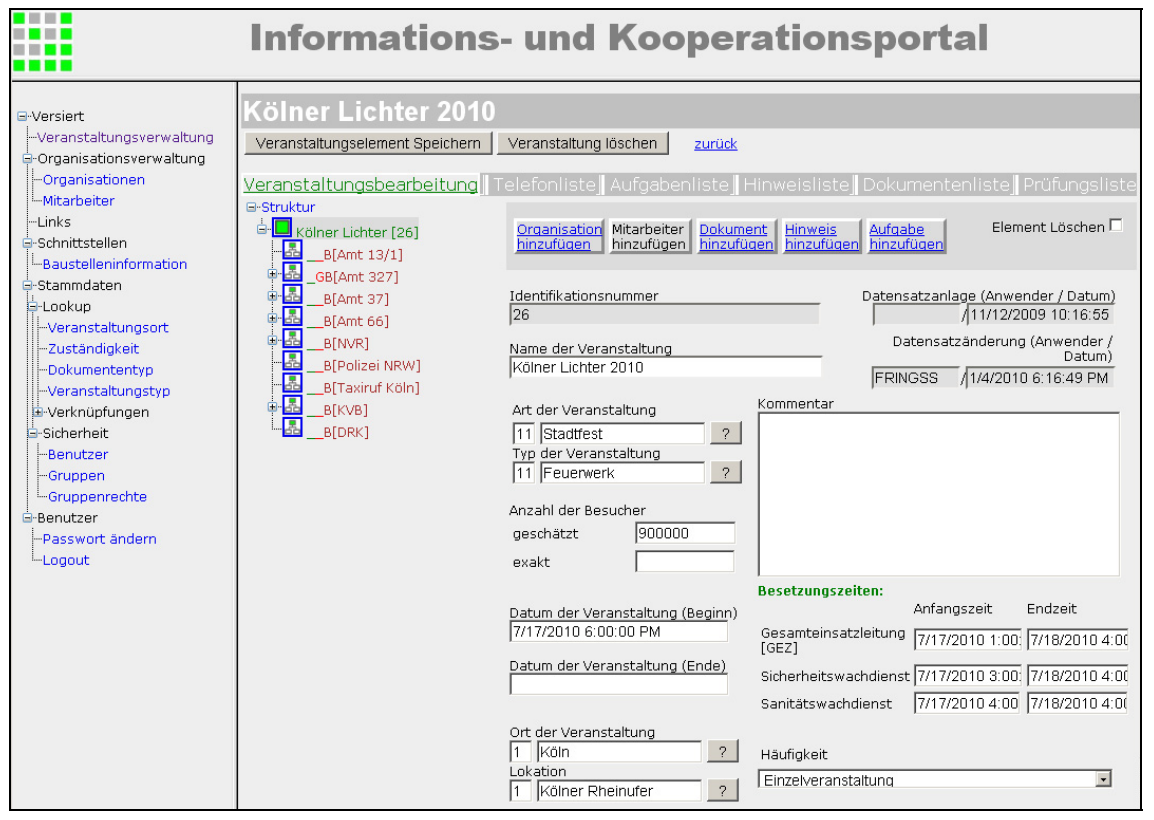

Figure 1: Screenshot of first portal demonstrator. 
administration of master date for persons and organisations, interfaces to external systems, and user and group administration.

Those technical requirements for and functions of the portal are documented in internal specification documents. Once those requirements were gathered, mock ups (GUI prototypes), and an entity relationship model were developed to discuss them with potential users of the system. This feedback gave valuable input for later implementation.

The portal's language is German, since the addressed users and also all VeRSiert partners are located in Germany. Figure 1 shows a screenshot of the December 2009 version of the demonstrator. During the presentation, the online demonstrator will be shown to the audience.

In addition to the functions mentioned above, there is also the possibility view relevant information on demand, for example, an event specific telephone list, or an organisation specific task list, or all available rules and advices, or recently uploaded documents. This means that all such filtered information can be displayed in a list according to its category.

\section{Outlook}

The information and cooperation portal for planning and executing a mass event follows the idea of being better prepared and more responsive in case of unplanned incidents. It therefore supplies relevant and up to date information, documents, contact details of relevant persons, etc.

The first demonstrator of the portal exists since the end of 2009, and the evaluation with the intended users is in progress. From this we expect to get feedback on the usability, if the portal provides relevant or irrelevant functions, if the portal misses important functions, if the users are able support their daily work (of planning or executing mass events) using the portal, etc.

In parallel, the second version of the demonstrator with more focus on unplanned incidents is being developed. The concept for incident handling in the portal focuses on creating and documenting scenarios for generic incidents. This may include background information, recommendations, and checklists if applicable. This way, event specific incident scenarios can be mentally prepared for by relevant persons, and it can be evaluated if the preparation is sufficient.

VeRSiert does not intend to develop systems already established, but to integrate links to those systems like early warning systems, alert systems, disaster recovery, and contingency planning systems. A major added value exists due to the focus on interorganisational information and communication processes, which are often not yet IT-supported.

Near the end of the project, the third version of the demonstrator will be available including new features and change requests mentioned and gathered in user as well as usability tests. Due to the two German surveys, also the transferability to other German Cities is addressed, and the transfer to other European Cities is subject to intended follow-up activities. 


\section{References}

[1] Kirchhof A., Gurzki Th., Hinderer H., Vlachakis, J. "Was ist ein Portal?" Definition und Einsatz von Unternehmensportalen, http://www.ebusiness.iao.fhg.de/fhg/Images/Was_ist_ein_Portal_tcm379-129040.pdf, 2008.

[2] Shilakes, C. C and Tylman, J. Enterprise Information Portals, Merrill Lynch, Inc., New York, NY, November 16, 1998.

[3] BBK (Bundesamt für Bevölkerungsschutz und Katastrophenhilfe, eds). Dritter Gefahrenbericht der Schutzkommission beim Bundesminister des Innern. Bericht über mögliche Gefahren für die Bevölkerung bei Großkatastrophen und im Verteidigungsfall, Band 59, Bonn, 2006.

[4] BMI (Bundesministerium des Inneren, eds). Schutz Kritischer Infrastrukturen - Basisschutzkonzept Empfehlungen für Unternehmen, Berlin, 2005.

[5] BMI (Bundesministerium des Inneren, eds). Rahmenkonzeption "Umsetzung der Handlungsempfehlungen zur Aufklärung und Beratung von Betreibern des öffentlichen Personennahverkehrs zur Früherkennung geplanter Anschläge”, 18.11.2005.

[6] BMI (Bundesministerium des Inneren, eds): Schutz Kritischer Infrastrukturen - Risiko- und Krisenmanagement Leitfaden für Unternehmen und Behörden, Berlin, 2007.

[7] BMI (Bundesministerium des Inneren, eds). Leitfaden zum vorbeugenden personellen Sabotageschutz im nichtöffentlichen Bereich, 2008.

[8] VDV VDV-Sicherheitsleitfaden für ÖPNV Unternehmen - Safety und Security, VDV M7018, 06/2008.

[9] Bailey, K. D. Monothetic and Polythetic Typologies and their Relation to Conceptualization: Measurement and Scaling, American Sociological Review, 38, 1, 18-33, 1973.

[10] Hevner, A. R., March, S. T., Park, J., AND Ram, S. Design Science in Information Systems Research, MIS Quarterly, 28, 1, 75-105, 2004.

[11] Rossnagel, H., Engelbach, W., Frings, S. Ortsbezogene mobile Dienste zur Verbesserung der Sicherheit bei Großveranstaltungen, in J. Roth (Eds.), Tagungsband 5. Fachgespräch Ortsbezogene Anwendungen und Dienste, Nürnberg, 35-40), 2008.

[12] Vaishnavi, V. and Kuechler, W. Design Research in Information Systems, http://www.isworld.org/Researchdesign/drisISworld.htm, January 20, 2004.

[13] http://de.wikipedia.org/wiki/Ordnungspartnerschaft

[14] http://www.polizei-nrw.de/im/Themen/Landessicherheitspreis/2008/article/ landespreis2008.html about the Cologne partnership "Verkehrssichere Städte und Gemeinden im Rheinland".

[15] http://www.vrr.de/de/service/sicherheit/sicher_unterwegs/index.html 